\title{
EXPANDING THE PARAMETERS OF PARENTAL ALIENATION SYNDROME
}

\author{
Glenn F. Cartwright \\ Department of Educational Psychology and Counselling, McGill University \\ 3700 McTavish, Montreal, QC, Canada H3A 1Y2
}

The American Journal of Family Therapy, 21(3), 205-215, 1993

\begin{abstract}
The newness of the parental alienation syndrome (PAS) compels its redefinition and refinement as new cases are observed and the phenomenon becomes better understood. New evidence suggests that alienation may be provoked by other than custodial matters, that cases of alleged sexual abuse may be virtual, that slow judgements by courts exacerbate the problem, that prolonged alienation of the child may trigger other forms of mental illness, and that too little remains known of the long term consequences to alienated children and their families.
\end{abstract}

Parental Alienation Syndrome (PAS), first defined by Gardner (1985), results from the attempt by one parent (usually the custodial parent and usually but not always the mother) to behave in such a way as to alienate the child or children from the other parent. It includes a series of conscious programming techniques like "brainwashing" as well as subconscious and unconscious processes by the alienating parent combined with the child's own contribution denigrating the allegedly hated parent (Gardner, 1992).

Gardner (1992) lists eight, broad manifestations indicative of PAS. First, there is a campaign of denigration in which there is the continuing profession of hatred of the absent parent by the child. This litany is easily evoked by teachers, lawyers, judges, or social workers and is often most strong in the presence of the "hated" parent. The child begins to withdraw from the lost parent, speaks indirectly ("You tell Daddy I don't want to see him"), and avoids taking clothes or toys home from the lost parent to avoid "contaminating" the favored parent. Chameleon-like (Johnston, Campbell, \&amp; Mayers, 1985), the child may initially experiment, denigrating each parent while with the other, covering his or her tracks by extracting promises from each not to tell the other. However, as the years go by, the child learns that what "sells" best is whatever tale is told in the custodial home - the home base where most of the child's time is spent. Children quickly learn on which side their bread is buttered.

Second, there are weak, frivolous, or absurd rationalizations given by the child for deprecating the lost parent. "He makes noise when he eats." "He took me to Disneyland when I didn't want to go." "He always talks about moon rockets." "He makes me take out the trash." This is the child's expression of a parallel phenomenon seen by lawyers in alienating parents: 
...in parental alienation syndrome, the hostility of the alienating client just never seems to be reasonably linked to the seriousness of the incidents alleged. The alienating client often relies blithely on his child's professed refusal to see the other parent as evidence of the inadequacy of the other parent (Goldwater, 1991, p. 125).

Coupled with this is a complete lack of ambivalence in both the alienating parent and the child which normally typifies all human relationships. Lawyers see it in their alienating clients:

The insistence upon the negative aspects of the spouse's character and behaviour coupled with the inability to see existing or even potential positive traits in the spouse are manifestations of an alienating attitude. Such a client appears to objectify his spouse as an evil thing, no longer a person with at least a few redeeming qualities. There is a loss of the ambivalence which characterizes healthy human relationships. Indeed, such objectification of the spouse as "all bad" should be taken to be a sign of significant disorder in the client himself (Goldwater, 1991, pp. 125-126).

Similarly, PAS children ...express themselves like perfect little photocopies of the alienating parent (Goldwater, 1991, p. 126) and can see no good in the lost parent and no bad in the loved parent. Given a list of "good" things the child did with the lost parent, the child will explain a few as being unenjoyable, others as being forced, still others as "all Dad's idea", and claim no memory of the rest. The process resembles amnesia wherein the child's good memories appear to be completely destroyed.

Fourth, there is the contention that the decisions to reject the parent are the child's. This is referred to by Gardner (1992) as the "Independent Thinker" phenomenon and is often invoked by alienating parents in courtroom testimony. "I want him to see his father but if he doesn't want to, I will fight to the end to ensure his decision is respected." However, as Goldwater (1991, p. 133) has argued:

No custodial parent would expect a judge to accept that the child be permitted not to attend school because he didn't feel like going. Why then should a judge accept that a child not visit his other parent for the same reason?

Children who claim to be their own thinkers often use words and phrases of the alienating parent which belie their claim. Similarly, alienating parents often act in ways as that indicate the idea to reject a parent was not the child's own. Says Gardner (1992):

Children are not born with genes that program them to reject a father. Such hatred is environmentally induced, and the most likely person to have brought about the alienation is the mother (p. 75). 
Fifth, there is an almost automatic, reflexive support by the child for the loved parent. Understandably, this reflexive support may flow either from a belief that the loved parent is an ideal person who can do no wrong or from the child's perception of the loved parent as the weaker of the two parents who needs defending.

Sixth, there is an almost complete absence of guilt regarding the feelings of the lost parent. "He doesn't deserve to see me." Gratitude for gifts, favors, or child support is non-existent. Gardner (1992) believes that:

The lack of guilt here is not simply explained by cognitive immaturity (often the case of very young children), but is a statement of the degree to which children can be programmed to such points of cruelty that they are totally oblivious to the effects of their sadism on innocent victims (p. 77).

Seventh, is the presence of borrowed scenarios. The litanies the children produce have a rehearsed, coached quality to them and often include expressions and phrases of the loved parent. "Daddy's new girlfriend is a whore!" Are these the words of a five-year-old?

Finally, there is an obvious spread of the animosity to the hated parent's extended family. "His mother called me a brat." Grandparents, aunts, uncles, and cousins are all tarred with the same brush as the child argues that all they do is try to get him or her to "like" the lost parent.

Though these are the classic manifestations PAS, the newly recognized nature of the syndrome compels its definitional refinement and enlargement as new parameters are discovered. This is especially important given the contention that the problem is growing in our society and now affects $90 \%$ of all children in custody litigation (Gardner, 1992). The following observations suggest that the parameters of PAS may be wider than previously believed.

\section{Parental alienation syndrome may be precipitated by parental disagreements on matters other than custody.}

It was originally suggested that PAS was a relatively new disorder emanating principally from changes in the criteria by which custody was decided. These criteria basically concerned the court's shift toward the best-interests-of-the-child presumption (favoring the placement of the child with the parent who would best meet the child's needs) at the expense of the tender-years presumption (always favoring the placement of the child with the mother), and the court's increasing preference for joint custody rather than sole custody placements. Since PAS is of a serious nature, it seemed reasonable to suppose that it would be provoked only by an equally serious emotional dispute, such as the question of custody is for most parents. However, while disagreement over custody remains implicated as the chief cause of PAS, it now appears that other, non-custodial disagreements on such matters as finance, property division, or child support may also trigger the syndrome by inducing an emotional climate conducive to PAS. This suggests that the etiology of PAS may be much broader than previously believed. If it is really the intensity of the emotional conflict between the estranged spouses which provokes PAS, then it must be wondered whether virtually any disagreement, serious or frivolous, may be a potential 
trigger. Similar parallels are found in other examples of human behavior: neighbors who stab each other over a noisy lawn mower and motorists who shoot each other over an illegal turn. To an observer, such consequent behavior is clearly out of proportion to the precipitating event. An illegal turn does not cause murder, but it may trigger an emotional state which does. So it may be with PAS. Whatever the precipitating disagreement, it may be just enough to trigger an irrational emotional state conducive to PAS.

Unfortunately, because PAS results from the interaction of the alienating parent with the child, wherein each reinforces the other, once the vicious circle has begun, it becomes self-reinforcing, complex to diagnose, and difficult to terminate. Complicating matters is the fact that PAS may be encouraged by third parties: a new spouse, new in-laws, or even unscrupulous lawyers whose wish it may be to extend rather than resolve the litigation.

\section{Allegations of fabricated sexual abuse may be virtual.}

Since the designation of PAS is inappropriate in cases where abuse is real, it has been customary (and necessary for the good of the child) first to distinguish between allegations of abuse that are real and those that are fabricated. Gardner (1991) has outlined how fabricated abuse may be detected. However, in the cases of fabricated abuse, a new and more subtle variety of allegation is beginning to appear. I have called these virtual allegations. They refer to those cases in which the abuse is only hinted, its real purpose being to cast aspersions on the character of the noncustodial parent in a continuing program of denigration. For the alienator, virtual allegations avoid the need to fabricate incidents of alleged abuse with their attendant possibility of detection and probability of punishment for perjury. For example, in one case, though no sexual abuse was ever alleged, it was hinted at in the allegation by the mother that the father had shown the child a rented videotape containing pornography. Though the videotape was a Hollywood comedy starring Chevy Chase rented from a family video store and chosen by the child, the mother asserted in court that the child was disappointed in the movie because it was suggestive, erotic, and pornographic. After interviewing the child extensively, the judge disagreed that the movie was pornographic and said that while the child was indeed disappointed with the film, it was not because the film was pornographic but because it wasn't funny. The number of virtual allegations of abuse may be expected to increase in the future because of their more subtle nature, the greater difficulty in disproving them, and because judges and lawyers familiar with PAS are becoming increasingly skilled at detecting outright fabrications.

\section{Time heals all wounds, except alienation.}

There is some evidence that adolescents who experienced parental separation most recently were most likely to be affected adversely (Frost \& Pakiz, 1990). While this tends to support the old adage that time heals all wounds, such is not the case with PAS, where the passage of time worsens rather than heals the affliction. This is not to say that time is unimportant: on the contrary, time remains a vital variable for all the players. To heal the relationship, the child requires quality time with the lost parent to continue and repair the meaningful association that may have existed since birth. This continued communication also serves as a reality check for the child to counter the effects of ongoing alienation at home. Likewise, the lost parent needs time with the child to ensure that contact is not completely lost and to prevent the alienation 
from completely destroying what may be left of a normal, loving relationship. Time used in these ways helps to counter the negative effects of alienation.

The alienating parent, on the other hand, requires time to complete the brainwashing of the child without interference. The manipulation of time becomes the prime weapon in the hands of the alienator who uses it to structure, occupy, and usurp the child's time to prevent "contaminating" contact with the lost parent, depriving both of their right to spend time together and furthering the goal of total alienation. Unlike cases of child abuse where time away from the abuser sometimes helps in repairing a damaged relationship, in PAS time away from the lost parent furthers the goal of alienation. The usual healing properties of time are lost when it is used as the primary weapon to inflict injury on the lost parent by alienating the child.

There is another reason why time is so important a weapon in the hands of the alienator. With the passage of time, the child grows to be staunch collaborator. A judge who might not listen to a nine-year-old pleading not to see his or her father, might be more disposed to listen to an older, "wiser", and more articulate thirteen-year-old. Spreading out the court proceedings over time not only aids in the brainwashing and contributes to the wearing down of the petitioner but ensures for the alienator a stronger child ally when a final court date is set.

So it is that time is often "bought" through false allegations, by assertions the child is in danger from contact with the lost parent, and by requests to the court for delays, continuances, and postponements. Sometimes even psychological assessment and psychiatric evaluation are pressed into service as part of the delaying tactic, then dropped when the sought-after delay has been achieved. On other occasions psycho-legal expertise is advanced ... with the psychologist cast as the hired gun engaged to put forth to the court the negative opinion of the contesting parent under the guise of an "expertise" (Goldwater, 1991, p. 123). The goal of the alienator is crystalline: deprive the lost parent, not only of the child's time, but of the time of childhood.

\section{The degree of alienation in the child is directly proportional to the time spent alienating.}

Alienation does not occur overnight. It is a gradual and consistent process that is directly related to the time spent alienating. The longer the child or children spend with the alienator, the more severe will be their alienation. Their supposed hatred of the lost parent does not lessen with time away from that parent but rather grows stronger, precisely because in the hands of the alienator they are continually taught hatred, have unlimited opportunity to practice that hatred, and have no time at all to learn an alternate response. This is one of the reasons why, in serious cases, Gardner (1992) recommends complete removal of the child from the alienating parent, with supervised visitation reinstated gradually.

\section{Courts slow to render judgements may unwittingly further the alienating parent's scheme of alienation.}

The court needs time too, to assess each case. Taking the best interests of the child to be paramount, and always moving cautiously, the court must ensure that the child is in no danger and determine if the case is truly one of parental alienation. But once the determination of PAS has been made, speedy judgement must be rendered to stop the alienation process immediately. 
Both the child and the petitioning parent deserve no less. Unfortunately, court postponements and continuances are more often the rule than the exception. Proceedings which are dragged out after a determination of PAS has been made, judgements which fail to take into account fully the rights of the non-custodial parent, and unnecessary interim judgements and delays, however well-intentioned, sadly tend to favor the continuation of the custodial parent's alienating behavior.

The judicial wish to maintain the status quo in the lives of children pending the outcome of hotly contested litigation may work in favour of an alienating custodial parent. The longer the children are in a non-supportive environment, the further they will drift away from their non-custodial parent (Goldwater, 1991, p. 130).

While there is no denying that courts have a difficult job at best, on balance it would appear that the prevailing tendency has been toward delaying judgement in the hope that the problem will go away, solve itself, or at the very least prove that no judgement is preferable to a wrong judgement. Courts must resist this tendency which doubtless is harmful to PAS children in the long run. More than two decades ago, Watson (1970, p.64) wrote of the court's slowness in rendering decisions:

The most serious aspect of these vacillating and dilatory tactics is the effect they have on the children. As will be noted, one of the critical aspects of a child's development is the need for stability in order to develop a sense of identity. When a child is kept suspended, never quite knowing what will happen to him next, he must likewise suspend the shaping of his personality. This is a devastating result and probably represents one of the greatest risks which current procedures pose for children.

Little seems to have changed: where PAS is concerned, it remains a case of "Justice delayed is lost parent denied."

\section{Forceful judgement is required to counter the force of alienation.}

The role of the court in cases of PAS goes beyond simply deciding custody issues. First, the precedent of clear, forceful judgement may deter some parents from beginning the alienation of their children. As Levy (1992, p. 277) has noted:

If parents who engage in PAS know that aware judges may give custody to the innocent parent, and perhaps even apply sanctions against parents who use a child to prevent the other parent's access to the child, the PAS, which is itself a form of child abuse, may suffer a fatal and well-deserved setback.

Second, clear and forceful judgements serve to put an immediate stop to the alienating practices (Palmer, 1988). Family courts can often be of great service in helping to work out a variety of 
family problems. However, in cases of PAS, courts which try to act as social workers using a "let's-talk-this-over-and-come-to-some-agreement" approach inevitably fail when one of the feuding parties is insincere and has little wish to solve the problem. The reason is that insincerity, conscious or unconscious, is one of the hallmarks of the alienating parent. While negotiation is often the solution in other forms of litigation, it tends not to work in cases of PAS. In these circumstances, the lack of a swift, clear, forceful judgment is often perceived by the alienator as denoting approval of the alienating behavior. This tends to reinforce the behavior and renders a great disservice to both the child and the petitioning parent. Courts must do more to help; they must not fall victim to the alienator's scheme of stalling for time in order to continue the program of vilification.

\section{Excessive alienation may trigger mental illness in the child.}

Johnston, Campbell, and Mayers (1985) reported that one response of latency children (6-12 years) to parental conflict was to act in a diffusely disturbed manner exhibiting anxiety, tension, depression, and psychosomatic illness. Consideration needs to be given to the question of what happens in the long run to children who are alienated. Is the problem self-limiting in that even alienation-caused wounds will heal as the child reaches adulthood? Unfortunately, alienation can become so powerful as to trigger other forms of mental and emotional illness with resultant maladaptive behavior. In one instance, an alienated son tried to poison his father by slipping air freshener into his stomach medicine. The boy later ran away during a non-custodial visit and the police had to be called. The likelihood of such disintegrating behavior during non-custodial visits increases in direct proportion to the amount of alienation experienced by the child at home.

\section{Little is known about the medium and long term effects of parental alienation syndrome on its victims.}

Perhaps the greatest gap in our understanding of the syndrome remains our lack of knowledge of what happens to the victims of PAS over the medium and long term. The short term consequences are known and obvious. The alienator experiences the sweetness of revenge and the thrill of "victory." The non-custodial parent experiences the anguish of the loss of a child, or worse, children. One set of grandparents, relatives, and friends are similarly affected and summarily dismissed. Far more serious is the effect on the child who experiences a great loss, the magnitude of which is akin to the death of a parent, two grandparents, and all the lost parent's relatives and friends, all at once! It can readily be seen that this represents a staggering loss for a child even greater than the actual death of one parent. Moreover, since the child is unable to acknowledge the loss, much less mourn it, it becomes a major tragedy of monumental proportions in the life of the child, the seriousness of which cannot be overestimated.

These are the known and relatively short term consequences. What about medium term effects? The medium term effects concern the continued absence (as opposed to initial loss) of the lost parent (and grandparents, relatives, and friends) and the effect this has on the child's development. Ordinary children who have grown up without a parent or grandparent often report "something missing" in their childhood. What is lost, of course, is the day-to-day interaction, the learning, the support, and the love that normally flows from parents and grandparents. While in 
the case of a death such loss is unavoidable, in the case of PAS such a loss is entirely avoidable and therefore inexcusable.

What about the long term effects? Everyone involved in PAS suffers some degree of distress over the long term. Hopefully, this includes the alienator who, despite the initial exhilaration of "winning," should hardly find the entire experience pleasurable. In later years, even if alienators do not experience some guilt or regret over their actions, they may develop some sympathy for their children of whom they deprived of a parent.

The non-custodial parent experiences both loss and yet continuing concern for the child. The anguish is akin to that felt by parents when a child goes missing. Since the lack of contact with the child may continue for years, the sense of loss can continue for a similar period. Grandparents suffer needlessly and often seriously. Gardner (1992) reports the cases of at least two grandmothers, in otherwise good health, who died of broken hearts, figuratively, over the loss of their grandchildren.

Of course, it is the child who suffers most. In the early stage, the child experiences not only loss of a parent, but the continual barrage of denigration of the lost parent, grandparents, relatives, and friends. Bad enough to lose a parent; worse still to have the good memories of that parent, relatives, and friends deliberately and systematically destroyed.

In the second stage, perhaps years later, the child begins to comprehend what has really happened. The realization of having believed the alienator, of having wrongly rejected the lost parent, and worse, of having been a pliable accomplice and willing contributor, can produce powerful feelings of guilt. The unfortunate consequences of these feelings may be a backlash against the alienating parent. Says Goldwater (1991, p. 128):

When such a child becomes an adult, the awareness of the enforced absence of the alienated parent for those many years may have a devastating impact and leave long-term feelings of guilt and loss. The alienating parent may then suffer the wrath his adult child feels for having precipitated this loss, and be in turn shut out of the child's life.

Serious emotional problems may ensue. For children to make a successful adjustment, an enormous task faces them: avoiding the tendency of the backlash response to the alienating parent, forgiving that parent, and maintaining a good relationship with that parent; and restoring good memories of the lost parent (which are often wiped out in PAS) and resuming a normal relationship with the lost parent if that parent is still alive, available, and willing. The re-establishment of the relationship with the lost parent is, naturally, a huge task. It involves making up for lost time and experiences, understanding cognitively and emotionally what has happened during the alienation process, re-learning how to interact with the lost parent, restoring a loving relationship, and planning the continuance of the relationship in the future. Therapy for both child and lost parent may be required. On top of this, the child must learn at this late date how to "juggle" the perhaps still feuding parents - a skill which most children of divorced parents usually learn much earlier. These are no small tasks and all this presupposes the child 
survives the teenage years without other serious emotional, mental, or behavioral problems which often accompany adolescence.

All being well, one would hope that eventual adjustment for these children would be possible. Negative factors which mediate against successful adjustment include the unwillingness or emotional inability of the lost parent to become reinvolved, the absence or death of the lost parent, and the passing on of the grandparents and other relatives and friends leaving an unfillable void in the life of the child.

\section{Further research is needed.}

While longitudinal studies have related child and adolescent adjustment following parental separation to a variety of variables such as age, gender, frequency and regularity of visitation (cf. Healy, Malley, \&amp; Stewart, 1990), what is so terribly lacking in the literature is any kind of longitudinal study to follow PAS children to ascertain what happens to them. What are the long term effects on these children as they enter adulthood? To what degree can their relationship with their lost parent be re-established? Is their relationship with the alienating parent permanently harmed in later adulthood? What happens to PAS children who permanently lose their non-custodial parent through death without ever re-establishing a relationship? Is their guilt intensified and if so, how do they handle it? Can their relationship with their lost parent, and for that matter with their alienating parent, ever approach normalcy? What does this do to their own parenting skills and how does it affect their bringing up their own children? If their relationship with their lost parent is not re-established, then the lost parent may eventually become a lost grandparent. What impact will this have on the grandchildren?

\section{The problem of parental alienation syndrome is much more serious than previously imagined.}

Viewed in this light, the problem of PAS appears to be extremely serious. We often speak of the preserving family values, but even disintegrated nuclear families have values and rights (like child visitation) which must be preserved and respected to prevent further disintegration and total collapse. To do less, is to sacrifice entire generations of children on the altar of alienation, condemning them to familial maladjustment and inflicting on them lifelong parental loss.

\section{References}

Frost, A.K. \&amp; Pakiz, B. (1990). The effects of marital disruption on adolescents: time as a dynamic. American Journal of Orthopsychiatry, 60(4), 544-555.

Goldwater, A. (1991). Le syndrome d'aliénation parentale (in English). Développements récents en droit familial (1991). Cowansville, QC: Les Éditions Yvon Blais. pp. 121-145.

Gardner, R. (1985). Recent trends in divorce and custody litigation. Academy Forum, 29(2): 3-7. 
Gardner, R. (1989). Psychotherapeutic and legal approaches to the three types of parental alienation syndrome families. In Family evaluation in child custody mediation, arbitration, and litigation. Cresskill, NJ: Creative Therapeutics.

Gardner, R. (1991). Parental alienation syndrome and the differentiation between fabricated and genuine child sex abuse. Cresskill, NJ: Creative Therapeutics.

Gardner, R. (1992). Parental alienation syndrome: A guide for mental health and legal professionals. Cresskill, NJ: Creative Therapeutics.

Healy, J., Malley, J., \& Stewart, A. (1990). Children and their fathers after parental separation. American Journal of Orthopsychiatry, 60(4), 531-543.

Johnston, J., Campbell, L., \& Mayers, S. (1985). Latency children in post separation and divorce disputes. Journal of the American Academy of Child Psychiatry, 24, 563-574.

Levy, D. (1992). [Review of Parental alienation syndrome: A guide for mental health and legal professionals.] American Journal of Family Therapy, 20(3), 276-277.

Palmer, N. (1988). Legal recognition of the parental alienation syndrome. American Journal of Family Therapy, 16(4), 360-363.

Watson, A.S. (1970). The children of Armageddon: Problems of custody following divorce. Syracuse Law Review, 21, 55-86. 